\title{
Using paleoecology to inform restoration and conservation of endangered heathlands
}

\author{
Cherié J. Dirk and Lindsey Gillson

\begin{abstract}
When restoring damaged or degraded ecosystems, land-use managers usually have a restoration target in mind. But how do they decide this target, and how do they know if it is realistic? This question is especially important when dealing with Renosterveld, a highly endangered component of the Fynbos biome in South Africa.
\end{abstract}

\section{Restoring a biodiversity-rich, but endangered, ecosystem}

Renosterveld is an evergreen, fire-prone Mediterranean-type shrubland, which is restricted to fertile, fine-grained soils of the Fynbos biome. The composition of Renosterveld generally includes grasses and a high diversity of endemic geophytes (bulbs), for example, of the genera Amaryllidaceae, Asparagaceae, Iridaceae, Hyacinthaceae, Orchidaceae, Oxalidaceae, and Geraniaceae, many of which are endemic, rare, or threatened. For example, of the Iridaceae, about $48 \%$ of the known species are listed as rare or threatened and about $76 \%$ are endemic to Renosterveld. Some bulb species (such as Freesia, Ixia, Ornithogalum, and Pelargonium) are economically important world cut-flowers (Rebelo et al. 2006). Unfortunately, 91-97\% of Renosterveld has been transformed for agriculture, so the remaining fragments are vital to the survival of this megadiverse biome. The species that currently dominates Renosterveld fragments is an evergreen, unpalatable shrub called Elytropappus rhinocerotis (Renosterbos). Little is known about the historic abundance and distribution of Renosterbos, leaving managers and conservationists to speculate on whether the current composition is typical and therefore a worthy conservation target, or whether restoration efforts are needed.

\section{A long-term understanding \\ of Renosterveld}

Very little is known about the history of Renosterveld, and whether what remains today is typical of its once much more extensive past. Though fire and herbivores are integral to Renosterveld ecology, it is difficult for land-use managers to know whether their prescribed grazing and burning regimes are appropriate to maintain such an extraordinary and unique species diversity. Furthermore, there are conflicting ideas of what Renosterveld vegetation should consist of - less or more grasses and shrubs (Cowling et al. 1986; Curtis 2013; Curtis and Bond 2013).

One way to resolve this dilemma is to look at long-term data to find out how Renosterveld looked and functioned ecologically prior to intensive management and land transformation, which began in the mid-17th century with the arrival of European settlers and further increased in the 20th century due to agricultural intensification. As there is little documented information from this period, long-term paleoecological data can be used to reconstruct how ecosystems looked in the past. Fossil pollen, coprophilous fungal spores, and charcoal from sediment cores can be used to reconstruct changes in the surrounding vegetation, herbivory (grazing) and fire regime. This multiproxy approach can be used to assess the relative importance of changing land use (specifically fire and herbivory) and climate in driving vegetation change.

\section{Elandsberg Private Nature Reserve as a case study}

Elandsberg Private Nature Reserve (PNR) is located in the Wellington District of the Western Cape, South Africa (Fig. 1), and contains one of the few and largest remaining fragments of West Coast Renosterveld. It is especially important because it is home to the critically endangered geometric tortoise (Psammobates geometricus), which is endemic to this region and one of the rarest tortoises in the world (Boycott and Bourquin 1988). The area has a long history of land use, with people managing fire and herbivory for more than 2000 years. Hunter-gatherers were in the region from 10,000-2000 yr BP (Deacon 1992) and land use further intensified with the arrival of the Khoikhoi pastoralists, who introduced livestock approximately 2000 yr BP (Cooke 1965; Elphick 1977; Boonzaier et al. 1996). With the arrival of European-settler agriculture from the mid-17th century, the region saw an increase in grazing pressure and grain crop cultivation, and combinations of fire suppression (to protect agriculture and property) in some areas and regular burning to promote pasture in others. In the 20th century, technology and industrialization allowed agricultural intensification and further transformation of natural vegetation.

A paleoecological study has now shed light on the history of the vegetation of Elandsberg PNR, providing important pointers for management and conservation in the future (Forbes et al. 2018). Pollen, charcoal, and fungal-spore data showed that the landscape of Elandsberg PNR today is still heavily influenced by human use, despite the area being a nature reserve since 1973. The data showed that Elandsberg PNR has been heavily transformed by farming since about the 1950s, when domestic livestock were abundant

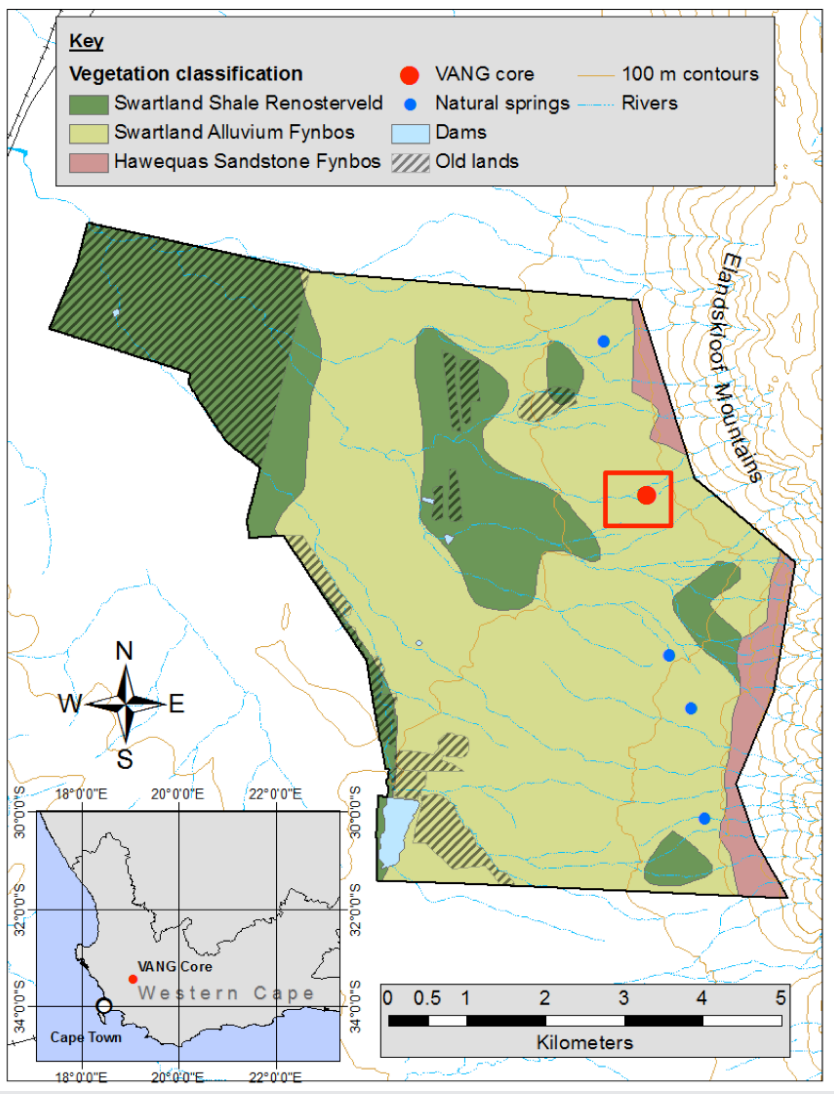

Figure 1: Map of Elandsberg PNR study site showing location of Vangkraal Spring wetland where the "VANG" sediment core was retrieved (red dot; $33.4383167 \mathrm{~S}$ and $19.068967 \mathrm{E}$ ). Diagonally crossed areas represent old lands that were previously cultivated. The red box represents the approximate study area. Figure reprinted from Forbes et al. (2018). 


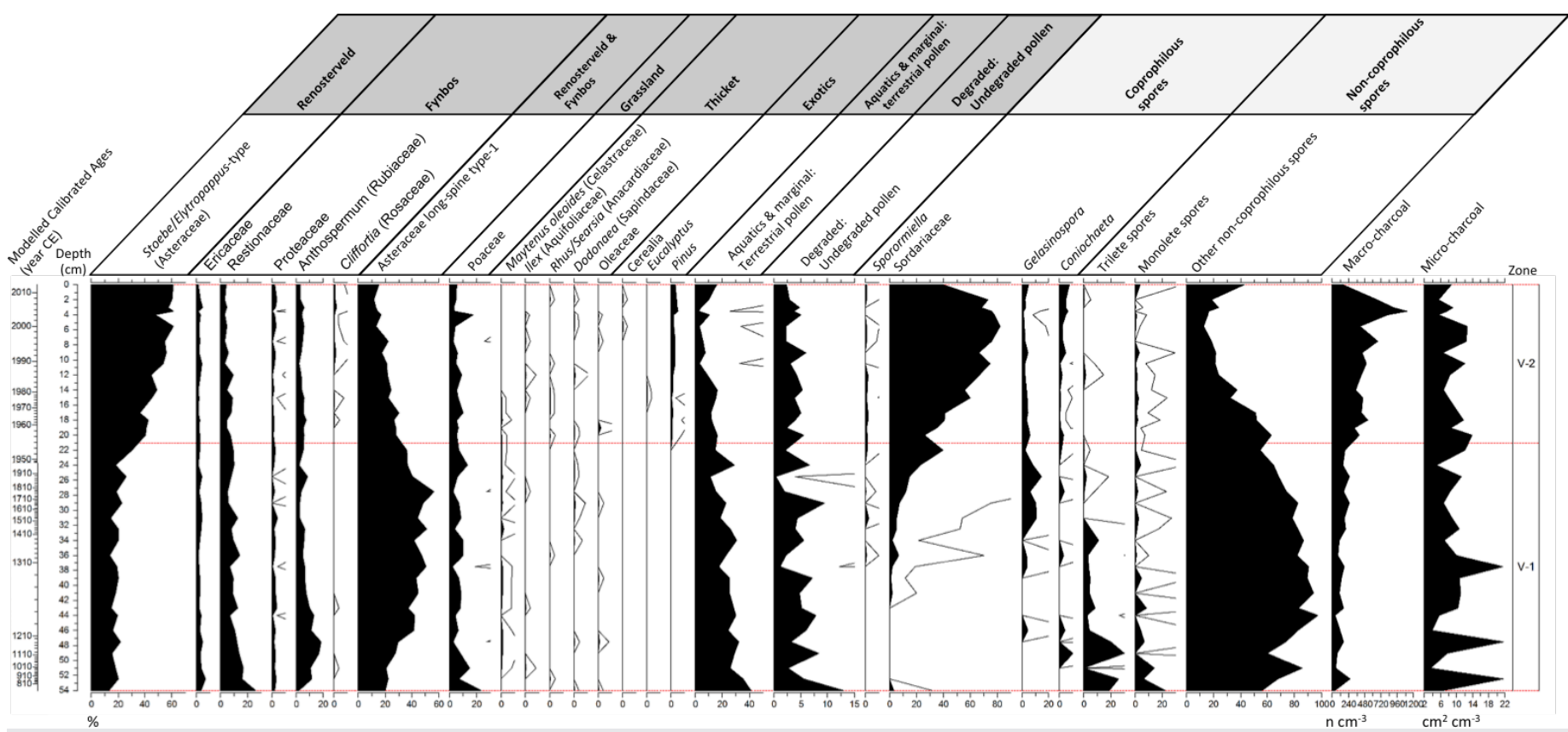

Figure 2: Percentage diagram for selected pollen taxa from the VANG core. The pollen sum included terrestrial and unknown pollen. True values have been multiplied by a factor of 10 since percentage values are often low for most taxa. Zonation is calculated by cluster analysis based on $70 \%$ minimum resemblance levels and is indicated by the dashed line and boxes V-1 and V-2 to the far right of the diagram. Troels-Smith (1955) stratigraphy is shown on the left as well as modeled calibrated ages that were determined using the age-depth model clam (Blaauw 2010).

(Fig. 2). Charcoal abundance increased dramatically at this time, suggesting that farmers started burning Renosterveld much more frequently, to improve grazing for cattle and sheep. This increase in herbivory and fire transformed the vegetation, specifically by causing a huge increase in the abundance of unpalatable Renosterbos (Elytropappus rhinocerotis) at the expense of other Renosterveld shrubs (Forbes et al. 2018).

Although the primary function for Elandsberg PNR was for the conservation of the geometric tortoise, when it became a nature reserve, managers replaced domestic livestock with re-introduced large indigenous herbivores including eland, blue and black wildebeest, zebra, red hartebeest, gemsbok, bontebok, and springbok (Fig. 1). Whether intentional or not, the fires at Elandsberg PNR (which were often caused by uncontrolled wild fires surrounding the reserve) remained high despite the transition from farming to conservation practices. Together with the high levels of herbivory caused by the re-introduced large indigenous herbivores, more fires resulted in the vegetation remaining in a transformed state - with abundant Renosterbos, and a less-diverse flora.

These results show that Elandsberg PNR was not in a typical state when the reserve was established. In fact the landscape of the 1970s was degraded by heavy grazing and frequent fire. Before the paleoecological project, reserve managers had no way of knowing that this was the case and assumed that the 1970s was a good baseline for their management goals. However, the paleoecological results show that a much better baseline and appropriate restoration target would be before intensive farming began in the 1950s, when herbivores were fewer, fire less frequent, and Renosterbos less abundant. If current high levels of grazing and fire continue, it is possible that the landscape will become further dominated by Renosterbos with associated loss of heterogeneity and biodiversity.

Looking ahead, Forbes et al. (2018) suggest that more experimental work is needed. Grazing exclosures and trials of different fire frequencies could help managers to find ways of reducing Renosterbos abundance and restoring vegetation to a more healthy state. Maintaining a diverse array of vegetation types in the reserve is good for Renosterveld biodiversity and also might help build resilience to future climate change. Therefore a flexible management approach and longterm monitoring at the patch and landscape level is recommended. Furthermore, future research using system dynamics modeling will provide decision-making support, allowing managers to explore the effects of future scenarios of changes in fire and grazing (Dirk et al. in prep).

Paleoecology provides a long-term perspective needed for restoration

Projects such as these show how short-term perceptions can mislead managers, to the detriment of biodiversity conservation. Most landscapes have been heavily transformed by people over the past century, and many have also been impacted by other stressors, such as climate change, and rising $\mathrm{CO}_{2}$ and Nitrogen deposition. Using 21 st century baselines for conservation and restoration targets could therefore be inappropriate. Restoration is an important component of conservation biology as it seeks to actively reverse degradation of an ecosystem, but accurate information is needed to inform managers about the historical range of variability of biodiverse landscapes, and the effects of human management in recent decades. Paleoecological research can provide context for interpreting recent changes and in developing restoration targets that conserve biodiversity and ecosystem services for future generations. Paleoecology can inform restoration targets by providing a window into how ecosystems functioned before heavy impact by people in the 20th century, and therefore guide future restoration. In the case of Renosterveld, managers can use paleoecological data to decide whether landscapes contain less or more, for example, grass, bulbs, grazing, or fire, to be at a healthy state that is resilient and sustainable in the future.

\section{AFFILIATION}

Plant Conservation Unit, Department of Biological Sciences, University of Cape Town, South Africa

\section{CONTACT}

Cherié Dirk: cheriedirk@gmail.com

\section{REFERENCES}

Blaauw M (2010) Quat Geochronol 5: 512-518

Boonzaier E et al. (Eds) (1996) The Cape herders: A history of the Khoikhoi of southern Africa. New Africa Books, $147 \mathrm{pp}$

Boycott RC, Bourquin O (1988) The South African tortoise book: A guide to South African tortoises, terrapins and turtles. Southern Book Publishers, 148 pp

Cooke CK (1965) Africa 35: 263-285

Cowling R et al. (1986) Biol Conserv 37: 363-377

Curtis O (2013) Management of Critically Endangered renosterveld fragments in the Overberg, South Africa (PhD Thesis). University of Cape Town

Curtis O, Bond W (2013) What is Renosterveld? Veld Flora 99: 180-183

Deacon HJ (1992) Philos Trans R Soc Lond B Biol Sci 337: 177-183

Elphick R (1977) Kraal and castle: Khoikhoi and the found ing of white South Africa (Ch 7). Yale University Press, $266 \mathrm{pp}$

Forbes CJ et al. (2018) Anthropocene 22: 81-93

Rebelo AG et al. (2006) In: Mucina L, Rutherford MC (Eds) The vegetation of South Africa, Lesotho and Swaziland. South African National Biodiversity Institute, 53-219

Troels-Smith J (1955) Danmarks Geologiske Undersogelse 3: 39-73 